\title{
The Association Between Contrast-induced Acute Kidney Injury and Neutrophil Gelatinase-associated Lipocalin
}

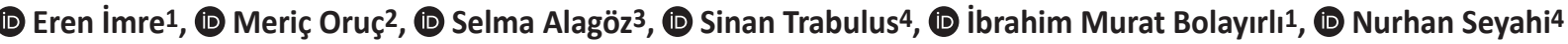 \\ 1istanbul University-Cerrahpaşa, Cerrahpaşa Faculty of Medicine, Department of Internal Medicine, İstanbul, Turkey \\ ${ }^{2}$ Kilis State Hospital, Clinic of Nephrology, Kilis, Turkey \\ 3 University of Health Sciences, İstanbul Bağcılar Training and Research Hospital, Clinic of Nephrology, istanbul, Turkey \\ 4 istanbul University-Cerrahpaşa, Cerrahpaşa Faculty of Medicine, Department of Nephrology, İstanbul, Turkey
}

\section{Abstract}

Objective: Neutrophil gelatinase-associated lipocalin (NGAL) has been reported as an useful marker to detect early contrast-induced acute kidney injury (Cl-AKI). However most of the studies were performed in subjects taking intraarterial contrast. We aimed to evaluate the role of serum NGAL for detection of Cl-AKI in patients undergoing contrast-enhanced computed tomography (CT).

Methods: We prospectively enrolled consecutive hospitalized patients with estimated glomerular filtration rate $\geq 15 \mathrm{~mL} / \mathrm{min} / 1.73 \mathrm{~m} 2$ undergoing contrast enhanced CT. Blood samples were taken before (baseline) and after 4 hours following procedure for NGAL and for serum creatinine ( $\mathrm{SCr}$ ) 12-24 hours prior to CT and again 48 hours after administration of contrast agent. The primary outcome of the study was the development of $\mathrm{Cl}-\mathrm{AKI}$.

Results: A total of 70 (male, 50\%) subjects with a mean age of $61.1 \pm 16.1$ years were enrolled. The mean baseline SCr was $1.02 \pm 0.39 \mathrm{mg} / \mathrm{dL}$. The incidence of $\mathrm{Cl}$-AKI was 5.7\%. In the whole group serum NGAL decreased from median 119.7 (IQR, 126.3) ng/mL at baseline to median 87.3 (interquartile range, 72.9) ng/mL after contrast application. Subjects were classified into those with and without CI-AKI. Subjects with Cl-AKI did not differ in baseline demographics, renal function, presence of systemic disorders and serum NGAL levels (baseline and $4 \mathrm{~h}$ ) compared with those without CI-AKI.

Conclusion: In conclusion, $4 \mathrm{~h}$ measurement of serum NGAL does not seem a useful marker for the early detection of CI-AKI following IV contrast administration.

Keywords: Neutrophil gelatinase-associated lipocalin, contrast-induced acute kidney injury, contrast-enhanced computed tomography

\section{INTRODUCTION}

Contrast-induced acute kidney injury (Cl-AKI) also known as contrast induced nephropathy has become the third leading cause of hospital acquired AKI, because of an increasing number of patients receiving intravascular injection of iodinated contrast media every year worldwide (1). Serum creatinine $(S C r)$ poorly reflects early changes in glomerular filtration and defines $\mathrm{AKI}$ before 24-48 hours (2) so considerable effort has been put into the search for new biomarkers as early indicators of AKI (3). One of the promising biomarker is neutrophil gelatinase-associated lipocalin (NGAL).

Although renal complications associated with intraarterial contrast administration have been reported mostly, there are few studies that examined the adverse oucomes of intravenous (IV) contrast administration after computed tomography (CT) procedures.

In our study, we aimed to determine the frequency of $\mathrm{Cl}-\mathrm{AKI}$ among patients who underwent an IV contrast-enhanced CT and to evaluate the role of serum NGAL for detection of Cl-AKI.

Phone: +90 5322963203 E-mail: nseyahi@yahoo.com ORCID ID: orcid.org/0000-0001-7427-618X

Cite this article as: İmre E, Oruç M, Alagöz S, Trabulus S, Bolayırlı iM, Seyahi N. The Association Between Contrastinduced Acute Kidney Injury and Neutrophil Gelatinase-associated Lipocalin. Eur Arch Med Res 2020; 36 (2):102-7

๑Copyright 2020 by the University of Health Sciences Turkey, Prof. Dr. Cemil Taşçığlu City Hospital

European Archives of Medical Research published by Galenos Publishing House. 


\section{METHODS}

Consecutive hospitalized patients undergoing elective CT with IV contrast administration at our institution between August 2012 and March 2014 were prospectively enrolled. Exclusion criteria were age $<18$ years; estimated glomerular filtration rate (eGFR) $<15 \mathrm{~mL} / \mathrm{min} / 1.73 \mathrm{~m}^{2}$, administration of iodinated contrast media within 7 days prior to study entry; history of anaphylaxis to iodinated contrast agent; lactation; evidence of acute kidney injury defined according to the Kidney Disease Improving Global Outcomes (2); acute myocardial infarction; administration of dopamine, mannitol or theophylline prior to procedure.

Demographic and clinical data were collected from patient files. These include age, gender, weight, relevant co-morbidities such as diabetes mellitus, hypertension, coronary artery disease and malignancy, current antihypertensive medications, diuretic usage. Pre and post procedure prophylaxes based on hydration and n-acetylcysteine (NAC) therapy were done according to the decision of the physician who followed up the patients.

Blood samples were obtained for SCr from all patients 12-24 hours prior to $\mathrm{CT}$ and again $48 \mathrm{~h}$ post-procedure. $\mathrm{SCr}$ was measured using the creatinine enzymatic assay (Jaffe ratemethod) in the Abbott C8000 analyzer (Abbott Diagnostics, Abbott Park, IL, USA). eGFR was calculated by using (Chronic Kidney Disease (CKD) Epidemiology Collaboration) formula (4)

Blood samples for NGAL evaluations were collected as baseline (within $1 \mathrm{~h}$ prior to CT imaging) and $4 \mathrm{~h}$ after CT imaging in ethylenediaminetetraacetic acid-anticoagulated tubes and centrifugation was carried out at 4500 cycles per minute for 10 minutes. The supernatant was separated and stored at $-80^{\circ} \mathrm{C}$ until assayed. On study time after the samples dissolved at room temperature, NGAL levels were measured by the enzymelinked immunosorbent assay (ELISA) technique, by using ELISA kit (Human Lipocalin-2/NGAL ELISA, number: RD191102200R @ BioVendor, Czech Republic). Subjects underwent contrastenhanced CT were administrated of iopamidol (Iopamiro ${ }^{\circledR}$, Santa Farma, Turkey) or iopromide (Ultravist ${ }^{\circledR}$, Bayer, United States) (300 mg of iodine per milliliter, nonionic, monomeric, low osmolality) at doses of $1 \mathrm{~mL}$ per kilogram of body weight.

The primary outcome of the study was the development of Cl-AKI by a rise in $\mathrm{SCr}$ of $\geq 0.5 \mathrm{mg} / \mathrm{dL}$ or a $\geq 25 \%$ increase from baseline value, assessed at 48 hours after a radiological procedure. This is the most widely used definition of $\mathrm{Cl}-\mathrm{AKI}$ in the literature (5).

The protocol was approved by the Ethics Committee of Cerrahpasa Medical Faculty (number: 16285, date: 11.06.2012). The study was performed in adherence to the Declaration of
Helsinki. Informed consent was obtained from all individual participants included in the study.

\section{Statistical Analysis}

Data were expressed as mean \pm standard deviation, median, interquartile range (IQR) and frequency. Data distribution was analysed with the Kolmogorov-Smirnov test. Comparison of different parameters were done using Mann-Whitney $U$ test whereas chi-square test or Fisher's exact test was used for categorical variables. The SPSS version of 22.0 for Windows software was used for analyses. Two tailed $p$ value $<0.05$ was considered statistically significant.

\section{RESULTS}

Seventy-five patients were recruited and consented, however 5 patients did not have follow-up blood testing for SCr. A total of 70 (male, $50 \%$ ) subjects with a mean age of $61.1 \pm 16.1$ years were enrolled. $24.3 \%$ of patients were diabetics, $40 \%$ had hypertension, $20 \%$ had malignacies, $24.3 \%$ had a history of coronary heart disease and $45.7 \%$ had infectious diseases. The mean baseline SCr was $1.02 \pm 0.39$ and the mean baseline eGFR was $76.7 \pm 30.9$ $\mathrm{mL} / \mathrm{min} / 1.73 \mathrm{~m}^{2}$. Forty-eight of 70 subjects $(68.6 \%)$ had a baseline eGFR of $\geq 60 \mathrm{~mL} / \mathrm{min} / 1.73 \mathrm{~m}^{2}$. The hydration and NAC therapy according to patient's status and clinician's decision were given to $61.4 \%$ and $47.1 \%$ of patients, respectively. The incidence of $\mathrm{CI}-\mathrm{AKI}$ was 5.7\%. Baseline demographic and clinical data of the study subjects grouped based on eGFR as $<60 \mathrm{~mL} /$ $\min / 1.73 \mathrm{~m}^{2}$ and $\geq 60 \mathrm{~mL} / \mathrm{min} / 1.73 \mathrm{~m}^{2}$ are shown in Table 1 . Patients with eGFR as $<60 \mathrm{~mL} / \mathrm{min} / 1.73 \mathrm{~m}^{2}$ received significantly more hydration therapy before contrast procedure and used significantly more diuretic drugs than patients with eGFR as $\geq 60$ $\mathrm{mL} / \mathrm{min} / 1.73 \mathrm{~m}^{2}$.

In the whole group serum NGAL decreased from median 119.7 (IQR, 126.3) ng/mL at baseline to median 87.3 (IQR, 72.9) after contrast application. Twenty-six patients (37.1\%) had a rise [median: $14.3(\mathrm{IQR}, 34.7) \mathrm{ng} / \mathrm{mL}$ ] in serum NGAL levels after CT imaging. For NGAL levels between baseline and after contrast exposure, we found a rise of $25 \%$ in 15 patients, a rise between $25-50 \%$ in 6 patients and a rise over $50 \%$ in 5 patients. In Figure 1 serum NGAL levels at baseline and $4 \mathrm{~h}$ with diagnosis of $\mathrm{CI}-\mathrm{AKI}$ is shown as a logarithmic scale.

Based on the primary outcome, subjects were classified into those with and without CI-AKI. Then we compared demographic characteristics (age, gender, weight), baseline renal function, presence of systemic disorders and serum NGAL levels (baseline and $4 \mathrm{~h}$ ) between patients with $\mathrm{Cl}-\mathrm{AKI}(\mathrm{n}=4)$ and patients 


\begin{tabular}{|c|c|c|c|c|}
\hline Variable & $\begin{array}{l}\text { All Patients } \\
n=70\end{array}$ & $\begin{array}{l}\text { eGFR }<60 \\
\mathrm{~mL} / \mathrm{min} / 1.73 \mathrm{~m}^{2} \\
\mathrm{n}=22\end{array}$ & $\begin{array}{l}\text { eGFR } \geq 60 \\
\mathrm{~mL} / \mathrm{min} / 1.73 \mathrm{~m}^{2} \\
\mathrm{n}=48\end{array}$ & $\mathrm{p}$ value \\
\hline Age, year & $61.1 \pm 16.1$ & $72.9 \pm 9.3$ & $55.7 \pm 15.8$ & 0.000 \\
\hline Male, n (\%) & $35(50)$ & $8(36.4)$ & $27(56.3)$ & 0.122 \\
\hline Weight, kg & $70.2 \pm 13.6$ & $73.5 \pm 16.7$ & $68.8 \pm 11.8$ & 0.183 \\
\hline Diabetes mellitus, n (\%) & $17(24.3)$ & $7(31.8)$ & $10(20.8)$ & 0.320 \\
\hline Hypertension, n (\%) & $28(40)$ & $12(54.5)$ & $16(33.3)$ & 0.093 \\
\hline Coronary artery disease, n (\%) & $17(24.3)$ & $8(36.4)$ & $9(18.8)$ & 0.111 \\
\hline Malignancy, n (\%) & $14(20)$ & $5(22.7)$ & $9(18.8)$ & 0.699 \\
\hline Infectious diseases, n (\%) & $32(45.7)$ & $11(50)$ & $21(43.8)$ & 0.626 \\
\hline ACE inh/ARBs usage, $n(\%)$ & $11(15.7)$ & $4(18.2)$ & $7(14.6)$ & 0.701 \\
\hline Diuretic usage, n (\%) & $15(21.4)$ & $9(40.9)$ & $6(12.5)$ & 0.007 \\
\hline Hydration therapy, n (\%) & $43(61.4)$ & $19(86.4)$ & $24(50)$ & 0.004 \\
\hline NAC therapy, n (\%) & $33(47.1)$ & $14(63.6)$ & $19(39.6)$ & 0.061 \\
\hline $\mathrm{eGFR}_{\text {baseline }}, \mathrm{mL} / \mathrm{min} / 1.73 \mathrm{~m}^{2}$ & $76.7 \pm 30.9$ & $42.4 \pm 10.8$ & $92.5 \pm 23.4$ & 0.000 \\
\hline $\mathrm{SCr}_{\text {baseline }}, \mathrm{mg} / \mathrm{dL}$ & $1.02 \pm 0.39$ & $1.44 \pm 0.34$ & $0.82 \pm 0.24$ & 0.000 \\
\hline $\mathrm{NGAL}_{\text {baseline }}, \mathrm{ng} / \mathrm{mL}$ & $119.7(126.3)$ & $120.9(111.9)$ & $113.9(162.8)$ & 0.548 \\
\hline $\mathrm{sCr} 48 \mathrm{~h}, \mathrm{mg} / \mathrm{dL}$ & $0.96 \pm 0.39$ & $1.36 \pm 0.34$ & $0.88 \pm 0.24$ & 0.000 \\
\hline $\mathrm{NGAL} 4 \mathrm{~h}, \mathrm{ng} / \mathrm{mL}$ & $87.3(72.9)$ & $100.6(62.5)$ & $86.6(113.3)$ & 0.752 \\
\hline Acute kidney injury, n (\%) & $4(5.7)$ & $2(9.1)$ & $2(4.2)$ & 0.585 \\
\hline
\end{tabular}

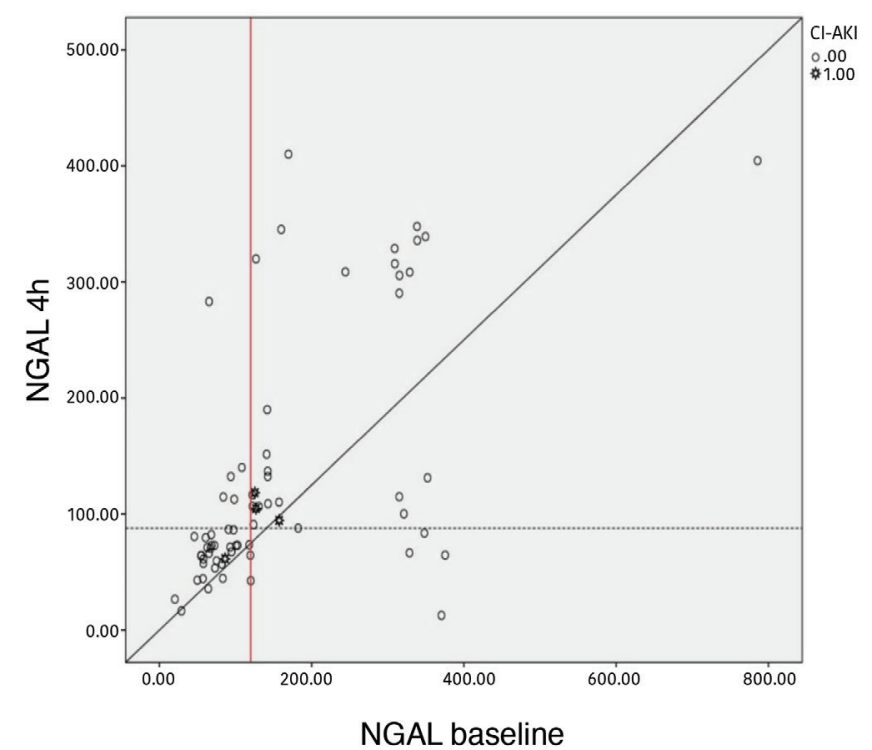

Figure 1. $\mathrm{NGAL}$ and $\mathrm{Cl}-\mathrm{AKI}$ diagnosis on a logarithmic scale. Dotted line: median level of serum NGAL $4 \mathrm{~h}$, red line: Median level of baseline serum NGAL

NGAL: Neutrophil gelatinase-associated lipocalin, Cl-AKI: Contrastinduced acute kidney injury without $\mathrm{Cl}-\mathrm{AKI}(\mathrm{n}=66)$. No significant differences were noted in studied variables (data were not shown). In Table 2, association of baseline serum NGAL levels with clinical variables was shown. Baseline serum NGAL was not found significantly associated with any clinical variable.

\section{DISCUSSION}

The frequency of $\mathrm{Cl}-\mathrm{AKI}$ in our patients undergoing IV contrastenhanced tomography was 5.7\%. The reported frequency of $\mathrm{Cl}-\mathrm{AKI}$ is $1-2 \%$ in patients with normal renal function, but increases up to $25 \%$ in patients with risk factors for instance the combination of CKD and diabetes, congestive heart failure, advanced age, and concurrent use of nephrotoxic drugs (6). By contrast to that associated with angiography, the risk of $\mathrm{Cl}-\mathrm{AKI}$ associated with contrast enhanced CT scans is quite low, even among patients with CKD $(7,8)$. Filiopoulos et al. (9) found CI-AKI in four subjects (8.5\%) in a population who underwent contrast enhanced $\mathrm{CT}$ and had well-preserved renal function. In another study, Weisbord et al. (8) found the frequency of AKI as 3.5\% in patients with eGFR less than $60 \mathrm{~mL} / \mathrm{min} / 1.73 \mathrm{~m}^{2}$ undergoing elective contrast-enhanced $\mathrm{CT}$. In addition three recent 


\begin{tabular}{|c|c|c|}
\hline \multicolumn{3}{|c|}{$\begin{array}{l}\text { Table 2. Association of baseline serum NGAL levels with clinical } \\
\text { variables }\end{array}$} \\
\hline Variable & $\begin{array}{l}\text { Baseline NGAL (ng/mL) } \\
\text { Median (IQR) }\end{array}$ & $p$ value \\
\hline \multicolumn{3}{|l|}{ Gender } \\
\hline Female & $119.9(162.2)$ & \multirow[t]{2}{*}{0.925} \\
\hline Male & $108.3(115.1)$ & \\
\hline \multicolumn{3}{|c|}{ Age, years } \\
\hline$\leq 74$ & 120.7 (130.3) & \multirow[t]{2}{*}{0.572} \\
\hline$>74$ & 118.9 (186.1) & \\
\hline
\end{tabular}

\begin{tabular}{|c|c|c|}
\hline \multicolumn{3}{|c|}{ Diabetes mellitus } \\
\hline Yes & $126.8(155.7)$ & \multirow[t]{2}{*}{0.742} \\
\hline No & $108.3(144.9)$ & \\
\hline \multicolumn{3}{|c|}{ Hypertension } \\
\hline Yes & 120.9 (198.9) & \multirow[t]{2}{*}{0.514} \\
\hline No & $110.3(132.5)$ & \\
\hline \multicolumn{3}{|c|}{$\begin{array}{l}\text { Coronary heart } \\
\text { disease }\end{array}$} \\
\hline Yes & $119.5(59.1)$ & \multirow[t]{2}{*}{0.598} \\
\hline No & $119.9(210.1)$ & \\
\hline \multicolumn{3}{|c|}{ Infectious diseases } \\
\hline Yes & $113.0(106.5)$ & \multirow[t]{2}{*}{0.782} \\
\hline No & $120.9(189.1)$ & \\
\hline
\end{tabular}

\begin{tabular}{|c|c|c|}
\hline \multicolumn{3}{|c|}{ Malignancy } \\
\hline Yes & $111.3(105.5)$ & \multirow[t]{2}{*}{0.971} \\
\hline No & $120.7(159.2)$ & \\
\hline \multicolumn{3}{|c|}{$\mathrm{SCr}_{\text {baseline }}, \mathrm{mg} / \mathrm{dL}$} \\
\hline$<1$ & $113.1(117.8)$ & \multirow[t]{2}{*}{0.348} \\
\hline$\geq 1$ & $119.7(195.0)$ & \\
\hline \multicolumn{3}{|c|}{$\mathrm{eGFR}_{\text {baseline, }}, \mathrm{mL} / \mathrm{min} / 1.73 \mathrm{~m}^{2}$} \\
\hline$<60$ & $120.9(111.9)$ & \multirow[t]{2}{*}{0.548} \\
\hline$\geq 60$ & $113.9(162.8)$ & \\
\hline
\end{tabular}

NGAL: Neutrophil gelatinase-associated lipocalin, SCr: Serum creatinine, eGFR: Estimated glomerular filtration rate, IQR: Interquartile range

prospective trials involving contrast enhanced CT with eGFR less than $60 \mathrm{~mL} / \mathrm{min} / 1.73 \mathrm{~m}^{2}$ found an overall incidence of $\mathrm{Cl}-\mathrm{AKI}$, of approximately 5\% (10-12). Interestingly, Muratoglu et al. (13) found $\mathrm{Cl}-\mathrm{AKI}$ as $16.2 \%$ in their study patients with no history of any renal disorder undergoing $\mathrm{CT}$ with contrast.

We know that SCr is not an optimal biomarker of kidney function and a change of $\mathrm{SCr}$ within 48 hours after contrast media injection might result in a delay for diagnosis Cl-AKI. Over $50 \%$ of kidney function must be lost before $\mathrm{SCr}$ begins to rise (14). Early detection of $\mathrm{Cl}-\mathrm{AKI}$ after contrast media exposure is important for appropriate intervention and prevention of the progress of renal impairment. So considerable effort has been put into the search for new biomarkers as early indicators of AKI.

NGAL is a 25-kDa protein produced by renal tubular cells in response to different types of injury (15). NGAL has been proved as an early, sensitive, non-invasive biomarker for AKI in different clinical settings such as in cardiac surgery $(16,17)$, critical care $(18,19)$, and kidney transplantation (20,21). Also it has been shown to be useful for earlier diagnosis in patients who underwent cardiac surgery and/or any procedure with intraarterial iodinated contrast material administration $(22,23)$. In a recent meta-analysis; NGAL level has been found as a valuable renal biomarker for predicting $\mathrm{Cl}-\mathrm{AKI}$ in patients who undergo percutaneous coronary intervention or coronary angiography (24). However; its performance in patients undergoing contrastenhanced CT is unclear.

Firstly Mishra et al. (25) reported a significant rise in serum and urinary NGAL in samples taken as early as $2 \mathrm{~h}$ after cardiopulmoner bypass surgery in children who developed acute renal injury. They also found a small but significant rise in samples taken similarly after the same procedure in children who never developed acute renal injury. The cause of this rising was believed to be the result of NGAL release in the bloodstream secondary to inflammatory activation of neutrophils. In another study, BachorzewskaGajewka et al. (26) also demonstrated significantly high NGAL levels in patients with $\mathrm{Cl}$-AKI starting $2 \mathrm{~h}$ (serum NGAL) or $4 \mathrm{~h}$ (urinary NGAL) after percutaneous coronary intervention. Similarly McCullough et al. (27) found that serum NGAL began to rise in plasma approximately $6 \mathrm{~h}$ after contrast exposure in paralel with a rise in $\mathrm{SCr}$ in subjects with eGFR $<75 \mathrm{~mL} / \mathrm{min} / 1.73$ $\mathrm{m}^{2}$ who underwent non-urgent coronary angiography. Alharazy et al. (28) had reported that serum NGAL at 4 hours did not change significantly in patients with stable CKD stages 2 to 4 who underwent coronary angiography then they found significant increase in serum NGAL at 24 hours and in $\mathrm{SCr}$ at 48 hours. Surprisingly, in $62.9 \%$ of our patients the concentrations of serum NGAL dropped after contrast application. Similarly to our study; Ribitsch et al. (29) found that only ten patients (1.62\%) undergoing intra-arterial angiography showed a significant rise of urinary NGAL and of whom one developed CI-AKI. They found decreased NGAL levels in parallel with urine osmolality so they suggested a diluting effect might be considered. According to meta-analysis recently published by Wang et al. (24), they hypothesized that the differences between these studies might be attributed to the dilution caused by adequate hydration however the hydration regimen has not been reported in most studies studies.

We know that there are major differences in patient populations, contrast volume administrated and intra-procedural 
complications between the two settings; contrast-enhanced CT and percutaneous coronary interventions. In Table 3, studies evaluating performance of NGAL predicting CI-AKI in patients undergoing contrast-enhanced CT. Firstly V. Filiopoulos et al. (9) demonstrated that plasma NGAL $6 \mathrm{~h}$ after contrast administration appeared to be a useful biomarker in the early prediction of $\mathrm{Cl}-\mathrm{AKI}$ in patients undergoing contrast-enhanced CT. Also Lacquaniti et al. (15) had reported that SCr levels showed a statistically significant increase 48 hours postcontrast whereas serum and urinary NGAL were early markers with their elevations observed after only 8 hours in their patients with stable stage 3 CKD undergoing CT with administration of iomeprol (AUC $=0.995$ and 0.992 for serum and urine NGAL, respectively). Muratoglu et al. (13) demonstrated that serum NGAL level increased at the $6 \mathrm{~h}$ and decreased at the $72 \mathrm{~h}$ in patients undergoing contrastenhanced with $\mathrm{CI}-\mathrm{AKI}$ ( $\mathrm{AUC}=0.98$ ). Our findings contrast these findings.

One major point of this new biomarker may be the fact that only little is known about predictive pattern or cut-off value in patients with underlying several co-morbidities such as inflammation, chronic heart disease, diabetes and CKD. Several investigators discovered a significant inverse relation between NGAL and renal function defined by eGFR (30). Because of the differences in the initial renal function, there is no effective method for integrating cut-off values (24). Ribitsch et al. (29) showed in their cohort that baseline urine NGAL levels were significantly associated with diabetes, lower GFR, cystatin C, proteinuria, age and female sex. However in our study, we did not find any association with baseline serum NGAL level and clinical variables.

Our study had some limitations. An important limitation is few sample size and the very few cases with $\mathrm{Cl}-\mathrm{AKI}(\mathrm{n}=4)$. A larger study population could make the results more reliable. According to previous studies as indicated before, mostly plasma NGAL appeared to be no sooner than $4 \mathrm{~h}$ after contrast exposure so serial mesurements would have been valuable. A large number of $\mathrm{Cl}$-AKI cases will be needed with blood NGAL mesurements to determine the risk.

\section{CONCLUSION}

In conclusion, $4 \mathrm{~h}$ measurement of serum NGAL does not seem a useful marker for the early detection of CI-AKI following IV contrast administration.

\section{Ethics}

Ethics Committee Approval: Ethics Committee of Cerrahpasa Medical Faculty (number: 16285, date: 11.06.2012).
Informed Consent: Informed consent was obtained from all individual participants included in the study.

Peer-review: Externally peer-reviewed.

\section{Authorship Contributions}

Surgical and Medical Practices: E.I., I.M.B., Concept: E.I., M.O., N.S., Design: E.I., M.O., S.A., N.S., Data Collection or Processing: E.I., I.M.B., N.S., Analysis or Interpretation: E.I., M.O., S.T., N.S., Literature Search: E.I., M.O., S.A., S.T., N.S., Writing: E.I., M.O., S.A., S.T., N.S.

Conflict of Interest: No conflict of interest was declared by the authors.

Financial Disclosure: The authors declared that this study received no financial support.

\section{REFERENCES}

1. McCullough PA, Sandberg KR. Epidemiology of contrast-induced nephropathy. Rev Cardiovasc Med 2003;4(Suppl 5):3-9.

2. Kidney Disease: Improving Global Outcomes (KDIGO) Acute Kidney Injury Work Group KDIGO Clinical Practice Guideline for Acute Kidney Injury. Kidney inter 2012;(Suppl 2):1-138.

3. Ralib AM, Pickering JW, Shaw GM, Devarajan P, Edelstein CL, Bonventre JV, et al. Test characteristics of urinary biomarkers depend on quantitation method in acute kidney injury. J Am Soc Nephrol 2012;23:322-33.

4. Levey AS, Stevens LA, Schmid CH, Zhang YL, Castro AF 3rd, Feldman HI, et al. A new equation to estimate glomerular filtration rate. Ann Intern Med 2009;150:604-12.

5. Ozkok S, Ozkok A. Contrast-induced acute kidney injury; A review of practical points. World J Nephrol 2017; 6:86-99.

6. Rudnick MR, Goldfarb S, Tumlin J. Contrast-induced nephropathy: is the picture any clearer? Clin J Am Soc Nephrol 2008;3:261-2.

7. Solomon R. Contrast-induced acute kidney injury: is there a risk after intravenous contrast? Clin J Am Soc Nephrol 2008;3:1242-3.

8. Weisbord SD, Mor MK, Resnick AL, Hartwig KC, Palevsky PM, Fine MJ. Incidence and outcomes of contrast-induced AKI following computed tomography. Clin J Am Soc Nephrol 2008;3:1274-81.

9. Filiopoulos V, Biblaki D, Lazarou D, Chrisis D, Fatourou M, Lafoyianni $S$, et al. Plasma neutrophil gelatinase-associated lipocalin (NGAL) as an early predictive marker of contrast-induced nephropathy in hospitalized patients undergoing computed tomography. Clin Kidney J 2013;6:578-83.

10. Barrett B, Katzberg RW, Thomsen HS, Chen N, Sahani D, Soulez G, et al. Contrast-induced nephropathy in patients with chronic kidney disease undergoing computed tomography: a double-blind comparison of iodixanol and iopamidol. Invest Radiol 2006;41:815-21.

11. Thomsen HS, Morcos SK, Erley CM, Grazioli L, Bonomo L, Ni Z, et al. The ACTIVE Trial: comparison of the effects on renal function of iomeprol-400 and iodixanol-320 in patients with chronic kidney disease undergoing abdominal computed tomography. Invest Radiol 2008;43:170-8.

12. Kuhn M, Chen N, Sahani DV, Reimer D, van Beek EJ, Heiken JP, et al. The PREDICT study: a randomized double-blind comparison of contrastinduced nephropathy after low- or isoosmolar contrast agent exposure. AJR Am J Roentgenol 2008;191:151-7. 
13. Muratoglu M, Kavalci C, Kilicli E, Findik M, Kayipmaz AE, Durukan P. Serum Neutrophil Gelatinase-Associated Lipocalin Levels In Early Detection of Contrast-Induced Nephropathy. Clin Invest Med 2016;39:88-94.

14. Filiopoulos V, Biblaki D, Vlassopoulos D. Neutrophil gelatinaseassociated lipocalin (NGAL): a promising biomarker of contrast-induced nephropathy after computed tomography. Ren Fail 2014;36:979-86.

15. Lacquaniti A, Buemi F, Lupica R, Giardina C, Murè G, Arena A, et al. Can neutrophil gelatinase-associated lipocalin help depict early contrast material-induced nephropathy? Radiology 2013;267:86-93.

16. Wagener G, Gubitosa G, Wang S, Borregaard N, Kim M, Lee HT. Urinary neutrophil gelatinase-associated lipocalin and acute kidney injury after cardiac surgery. Am J Kidney Dis 2008;52:425-33.

17. Bennett M, Dent CL, Ma Q, Dastrala S, Grenier F, Workman R, et al. Urinary NGAL predicts severity of acute kidney injury after cardiac surgery: a prospective study. Clin J Am Soc Nephrol 2008;3:665-73.

18. Zapitelli M, Washburn KK, Arikan AA, Loftis L, Ma Q, Devarajan P, et al. Urine neutrophil gelatinase-associated lipocalin is an early marker of acute kidney injury in critically ill children: a prospective cohort study. Crit Care 2007;11:84.

19. Siew ED, Ware LB, Gebredsadik T, Shintani A, Moons KG, Wickersham $\mathrm{N}$, et al. Urine neutrophil gelatinase-associated lipocalin is an erly marker of acute kidney injury in critical ill adults. J Am Soc Nephrol 2009;20:1823-32.

20. Parikh CR, Jani A, Mishra J, Ma Q, Kelly C, Barasch J, et al. Urine NGAL and IL-18 are predictive biomarkers for delayed graft function following kidney transplantation. Am J Transplant 2006;6:1639-45.

21. Hall IE, Yarlagadda SG, Coca SG, Wang Z, Doshi M, Devarajan P, et al. IL-8 and urinary NGAL predict dialysis and graft recovery after kidney transplantation. J Am Soc Nephrol 2010;21:189-97.

22. Schilcher G, Ribitsch W, Otto R, Portugaller RH, Quehenberger F, Truschnig-Wilders $M$, et al. Early detection and intervention using neutrophil gelatinase-associated lipocalin (NGAL) may improve renal outcome of acute contrast media induced nephropathy: a randomized controlled trial in patients undergoing intra-arterial angiography (ANTICIN Study). BMC Nephrol 2011;12:39.

23. Haase-Fielitz A, Bellomo R, Devarajan P, Story D, Matalanis G, Dragun $D$, et al. Novel and conventional serum biomarkers predicting acute kidney injury in adult cardiac surgery--a prospective cohort study.Crit Care Med 2009;37:553-60.

24. Wang K, Duan CY, Wu J, Liu Y, Bei WJ, Chen JY, et al. Predictive Value of Neutrophil Gelatinase-Associated Lipocalin for Contrast-Induced Acute Kidney Injury After Cardiac Catheterization: A Meta-analysis. Can J Cardiol 2016;32:1033.19-29.

25. Mishra J, Dent C, Tarabishi R, Mitsnefes MM, Ma Q, Kelly C, et al. Neutrophil gelatinase-associated lipocalin (NGAL) as a biomarker for acute renal injury after cardiac surgery. Lancet 2005;365;1231-8.

26. Bachorzewska-Gajewska H, Malyszko J, Sitniewska E, Malyszko JS, Poniatowski B, Pawlak K, et al. NGAL (neutrophil gelatinase-associated lipocalin) and cystatin C: are they good predictors of contrast nephropathy after percutaneous coronary interventions in patients with stable angina and normal serum creatinine? Int J Cardiol 2008;127:2901.

27. McCullough PA, Williams FJ, Stivers DN, Cannon L, Dixon S, Alexander $P$, et al. Neutrophil gelatinase-associated lipocalin: a novel marker of contrast nephropathy risk. Am J Nephrol 2012;35:509-14.

28. Alharazy SM, Kong N, Saidin R, Gafor AH, Maskon O, Mohd M, et al. Neutrophil gelatinase-associated lipocalin as an early marker of contrast-induced nephropathy after coronary angiography. Angiology 2014;65:216-23.

29. Ribitsch W, Schilcher G, Quehenberger F, Pilz S, Portugaller RH, Truschnig-Wilders M, et al. Neutrophil gelatinase-associated lipocalin (NGAL) fails as an early predictor of contrast induced nephropathy in chronic kidney disease (ANTI-CI-AKI study). Sci Rep 2017;7:41300.

30. Bolignano D, Lacquaniti A, Coppolino G, Donato V, Campo S, Fazio MR, et al. Neutrophil gelatinase-associated lipocalin (NGAL) and progression of chronic kidney disease. Clin J Am Soc Nephrol 2009;4:337-44. 